\title{
Real Academia Española (2005): Diccionario del estudiante, Barcelona, Santillana.
}

En los últimos años, la lexicografía didáctica ha experimentado un avance notable. Desde que Humberto Hernández (1992) dio a conocer su estudio sobre los diccionarios que estaban en el mercado hasta entonces, los autores de diccionarios han tomado conciencia de la importancia de elaborar diccionarios específicos para un tipo de usuarios cuyas necesidades se podían definir con cierta nitidez. ${ }^{1}$ Los resultados han sido visibles, y hoy el español dispone de buenos diccionarios escolares. En este contexto, el Diccionario del estudiante (DEst) publicado por la Academia ocasiona la presentación de elementos positivos y esperanzadores por lo que respecta a los trabajos académicos venideros, lo que contrasta con el hecho de que la huella del modo académico tradicional de confeccionar los diccionarios sea todavía visible.

En relación con los diccionarios académicos, el DEst puede considerarse una obra singular en la que subyacen dos novedades interrelacionadas: por una parte, es un diccionario dirigido a estudiantes hispanohablantes de enseñanza secundaria, de edades comprendidas entre 12 y 18 años, y, por la otra, es una obra lexicográfica de nueva planta, lo que significa que las definiciones de las voces recogidas han sido redactadas de primera mano y sometidas a una metodología nueva. Por lo tanto, en el DEst se aplica uno de los mayores logros de la lexicografía en los últimos años: que el objetivo principal de los diccionarios sea satisfacer las necesidades específicas de un grupo de usuarios, diversas de las que puedan tener otros. ${ }^{2}$

En lo referente al usuario al que se dirige, el DEst no representa una novedad editorial, a pesar de que es la primera obra publicada por la Academia con este título, ${ }^{3}$ ya que en el mercado se encuentran diccionarios con designaciones parecidas: el Diccionario del estudiante de la lengua española ${ }^{4}$ (1997) editado por Larousse o el Diccionario del estudiante de la lengua española $(C D-R O M)^{5}(2003)$ editado por Vox. ${ }^{6}$ En cuanto a la edad de los destinatarios del DEst, hubiera sido más apropiado que la Academia hubiera limitado la obra a un perfil de

\footnotetext{
* Este estudio se inserta en el marco del proyecto de investigación Diccionario histórico del español moderno de la ciencia y de la técnica, desarrollado por el grupo NEOLCYT (http://seneca.uab.es/neolcyt), Grupo Consolidado de la Generalitat de Catalunya (2005SGR 00823), y financiado por el Ministerio de Educación y Ciencia (HUM2004-00486).

${ }^{1}$ Como corroboran los estudios de Hernández (2000 y 2003), Maldonado (2003), Castillo Carballo y García Platero (2003) y Sánchez Muñoz (2002-2003), entre otros, los diccionarios didácticos ya no son el resultado de reducir la macroestructura de los diccionarios generales.

${ }^{2}$ La supeditación de la lexicografía a los destinatarios de las obras es una situación expresada por varios estudiosos, entre otros Gutiérrez Cuadrado (1996: 95-96), Garriga (1999: 43), Hernández (2000: 103-106) o Maldonado (2003: 133).

${ }^{3}$ Quizás hubiera sido más adecuado usar el término escolar en lugar de estudiante, pues mientras éste se refiere a la persona que estudia, aquél lo hace al «alumno que asiste a la escuela para recibir la enseñanza obligatoria» (DRAE-2001). En esta línea se dirige el comentario de Hernández (2003: 9), aludiendo a los diccionarios para estudiantes nativos como diccionarios escolares.

${ }^{4}$ Enfocado a estudiantes de ESO, Bachillerato, FP y a estudiantes de español como lengua extranjera, incluye 25000 palabras y más de 40000 definiciones. Contiene ejemplos en todas las definiciones, sinónimos y antónimos, familias de palabras y observaciones gramaticales. Incluye 32 láminas temáticas a todo color.

${ }^{5}$ Permite la realización de consultas gramaticales (ortografía, morfología y sintaxis), la consulta de un conjugador verbal y la puesta a prueba de los conocimientos de lengua mediante un juego.

${ }^{6}$ Posteriormente, se ha publicado el Diccionario universal del estudiante (2006) editado por Texto Editores y destinado a estudiantes de secundaria y de bachillerato, con unas 30000 entradas.
} 
usuario más restringido, ${ }^{7}$ pues existen muchas diferencias entre los contextos referidos a la Enseñanza Secundaria Obligatoria (de 12 a 16 años) y al Bachillerato (de 16 a 18 años), lo que conlleva que la formalización de la información destinada al alumno de 12 años pueda no serle útil al de 18, y viceversa (Sánchez Muñoz, 2002-2003).

A continuación se exponen de forma más detallada las características del DEst.

\section{HiPERESTRUCTURA}

La exposición de la organización general de la información en el DEst (hiperestructura) cuenta con diversos apartados. Antes del diccionario propiamente dicho, se ofrecen varios párrafos con la intención de que el usuario pueda aprovechar las informaciones que contiene: algunos artículos de muestra que ilustran los pormenores de la confección del artículo lexicográfico; una explicación sobre qué es el DEst; unas instrucciones sobre cómo usarlo; una lista de abreviaturas; y, finalmente, una relación de los signos empleados que, si se piensa en su descodificación inequívoca, se aprecia demasiado compleja. Dispone también de tres apéndices (Numerales, Conjugación verbal y Ortografía), cuya conexión con el cuerpo del diccionario es poco perceptible, contrariamente con lo que sucede en una obra como el Diccionario didáctico del español. Intermedio (1996) de SM. En el cuerpo del DEst se remite a los modelos de conjugación del apéndice correspondiente a los verbos - excluir (conjug. CONSTRUIR)-, pero, en cambio, en las entradas no se envía a los cuadros de conjugación en los que aparecen los verbos irregulares, ni se lematizan las formas anómalas de verbos difícilmente identificables (como anduve, quepo o voy). A este respecto, aunque el hablante nativo interioriza inconscientemente las reglas gramaticales de su idioma - sin embargo, en casos como anduve la regularidad del paradigma, *andó, parece imponerse hasta una cierta etapa-, la interrelación entre las estructuras del diccionario puede ayudar a que el estudiante aproveche las informaciones que contiene mediante la remisión de la macro o microestructura a la hiperestructura, y viceversa. De este modo, se le ofrece la posibilidad de ir de la consulta aislada de una forma irregular a su ubicación en su paradigma, y al revés. Por otro lado, las instrucciones para el usuario son claras, pero una introducción a la gramática del español o un apéndice gramatical como el que se ofrece en el Diccionario para la enseñanza de la lengua española (DIPELE) dirigido por Manuel Alvar Ezquerra (1995) hubieran sido fructíferos, ya que permitiría al estudiante de español combinar los contenidos gramaticales con los meramente léxicos de un modo cómodo y rápido.

\section{MACROESTRUCTURA}

El hecho de que la obra se dirija a estudiantes hispanohablantes de enseñanza secundaria, con el objetivo de introducirlos «en el maravilloso mundo de la palabra y guiarlos en el conocimiento de nuestro idioma» (DEst: IX), ha supuesto que la Academia haya tenido que realizar una labor de selección del vocabulario a partir de la consideración del léxico más usual de dichos estudiantes. Esta delimitación aproxima al DEst a muchos de los rasgos característicos

${ }^{7}$ A este respecto, Hernández (2000: 104) defiende la elaboración de diccionarios diferenciados por niveles escolares, de modo que puedan llevarse con éxito los procesos de descodificación y los de codificación. En esta línea se encamina la serie de diccionarios elaborada por la editorial SM, constituida por los diccionarios Básico (8-12 años), Intermedio (12-16 años) y Avanzado (16 años en adelante). 
de los diccionarios de aprendizaje de español como lengua extranjera -como el DIPELE (1995) o el Diccionario Salamanca de la lengua española (DISALE) dirigido por Juan Gutiérrez Cuadrado (1996) - y a los de los diccionarios escolares -como el Diccionario didáctico del español. Intermedio (1996) o el Diccionario didáctico de español. Avanzado (1997), ambos editados por SM y dirigidos por Concepción Maldonado-- Sin embargo, a partir de la consideración del prestigio y del carácter normativo de que goza el criterio de la Academia para la comunidad hispanohablante -«incluye la información de normas básicas de corrección lingüística que debe conocer un estudiante de habla española» (DEst: XV)-, el DEst no puede registrar palabras o acepciones no recogidas en el $D R A E$ o, a lo sumo, en los ficheros académicos actuales. Para su constitución, según declara el propio diccionario, se han estimado los datos del Corpus de Referencia del Español Actual (CREA) y se ha creado ad hoc un banco de datos léxicos específico «integrado exclusivamente por libros de texto de todas las materias» (DEst: XV).

El DEst, como se afirma en su presentación (Xv), contiene más de 40000 lemas, destacados en un cuerpo de letra mayor que el resto de palabras y en color azul, y solo incluye voces o acepciones que se encuentran en el $D R A E$ o en otros diccionarios publicados por la Academia. De su lemario, sensiblemente superior a las aproximadamente 30000 entradas $^{8}$ de los diccionarios monolingües de aprendizaje de E/LE, se desprende la idea de que es una obra que excluye muchas palabras arcaicas, técnicas, dialectales e incluye los vocablos más frecuentes del español, como corresponde a un diccionario de estas características. Las voces y acepciones arcaicas vienen marcadas con histór. ('ámbito histórico'), marca usada por primera vez en la lexicografía académica bajo los términos que se conservan actualmente para designar realidades del pasado, como adarga, auriga, calendas, encomendero, suevo o sufragismo. Se han suprimido las marcas ant. ('anticuado') y desus. ('desusado') del $D R A E-2001$, junto con las acepciones a las que acompañaban, pues en cuanto a ant. ya no se encuentran voces como arrufadia, difamia o disparcialidad ni las acepciones de acuciar (5) 'cuidar con diligencia', artificial (4) 'artificioso' o malmeter (3) 'malbaratar, malgastar', y con respecto a desus. no se hallan las voces enaspar, friura o limpiamiento ni las acepciones de minuto (1) 'menudo, en monedas pequeñas', organizar (4) 'disponer el órgano para que esté acorde y templado' o plan (13) 'plano, representación esquemática'. Pero si tenemos en cuenta el tipo de diccionario de que se trata, la representación adecuada del léxico de la sociedad contemporánea (léxico coloquial actual, vulgar, tecnicismos, extranjerismos, americanismos o siglas) merece una atención mayor. Aunque en la introducción al DEst se pone especial énfasis en que se recoge el léxico actual, los criterios que se han seguido para elegir el vocabulario que se incluye, aspecto fundamental en los diccionarios didácticos, no se explicitan. Ciertamente, es importante anunciar cuántas palabras reúne el diccionario, pero no lo es menos dar a conocer cómo se han seleccionado. El desconocimiento de los criterios de selección de unas voces y no de otras provoca que los motivos por los cuales no se incluyen palabras tan recientes y usadas como cambio climáti-

${ }^{8}$ Los dos únicos diccionarios monolingües de aprendizaje de E/LE que exponen en sendos prólogos cuántos lemas recogen son el DIPELE, y el DISALE, con 22000 y 34500 , respectivamente. En la información promocional del Diccionario de la lengua española para estudiantes de español (DILEPEE), coordinado por Villar (2002), se afirma que la obra está compuesta por 24000 entradas. El Diccionario de español para extranjeros (DEPE), dirigido por Maldonado (2002), debido a sus dimensiones físicas y número de páginas, muy parecidas al DIPELE y al $D I L E P E E$, recoge aproximadamente un número muy similar de entradas, esto es, entre 20000 y 25000. 
co, tsunami o violencia doméstic $a^{9}$ resulten injustificables, a menos que se conozcan los criterios tradicionales de la Academia para la aceptación de neologismos.

En cuanto al léxico coloquial, se registran muchos vocablos propios de jergas, como boli, guay o tío, que los usuarios de estas edades emplean, pero se obvian otros hoy muy usuales, como botellón (ausente en el DRAE-2001) 'reunión de gente al aire libre para consumir bebidas alcohólicas', rallar (presente en el $D R A E$-2001) 'molestar, fastidiar con importunidad y pesadez' o tronco (ausente en el DRAE-2001) 'amigo'. Otro ejemplo se encuentra en las voces relacionadas con el alcohol: se incluye castaña, cogorza, mona, pedo y trompa pero no, en cambio, pedal, tajada (presente en el DRAE-2001) o toña.

Por lo que respecta al tratamiento de los tecnicismos, ${ }^{10}$ de los cuales el DEst dice recoger los más difundidos, se omiten términos tan comunes entre los jóvenes de hoy como bajar y subir/colgar 'descargar (archivos de Internet)/incluir (archivos en Internet)' -aunque sí se halla la acepción de colgar 'bloquearse un ordenador', como en el DRAE-2001-, así como términos divulgados en los últimos años con frecuencia en los medios de comunicación, como gripe aviaria, también llamada gripe del pollo, que sustituyen a conceptos muy técnicos, en este caso concreto para referirse a la enfermedad que padecen las aves causada por el virus H5N1. Esta última ausencia contrasta con la presencia de un término muy similar como vaca loca, mamífero rumiante bóvido que padece la encefalopatía espongiforme bovina. En el área de los subcampos temáticos, la Academia explicita por primera vez la inclusión de indicaciones que introducen las acepciones de algunas actividades que forman parte de subámbitos dependientes de otros incluidos en la lista de marcas de especialidad, i.e. la presencia del ámbito «fútbol» dentro del de «deportes», como en centrocampista «m. y f. En fútbol: Jugador que actúa...». Compárense las indicaciones temáticas siguientes entre el DEst y el DRAE-2001:

\begin{tabular}{|l|l|l|}
\hline \multicolumn{1}{|c|}{ Voz } & \multicolumn{1}{|c|}{ DEst } & \multicolumn{1}{c|}{ DRAE-2001 } \\
\hline entrada & 13. En algunos deportes & 25. f. Dep. En algunos deportes \\
\hline entrar & 18. Dep. & $\begin{array}{l}\text { 29 tr. Dep. Dicho de un jugador: En el fútbol y } \\
\text { otros deportes }\end{array}$ \\
\hline juego & 6. En tenis & 13. . Dep. En el tenis y otros deportes \\
\hline manga & 5. El algunos deportes & 16. f. Dep. En diversos deportes \\
\hline palo & 5.Dep. & 15.m. Dep. Especialmente en el fútbol \\
\hline ría & 2. Dep. & 3. f. Dep. En ciertas competiciones deportivas \\
\hline
\end{tabular}

En estos ejemplos se aprecia una reducción de las acepciones, coherente con el tipo de diccionario, y una revisión del tratamiento de estas indicaciones temáticas en el DEst con respecto al $D R A E-2001$, pero siguen observándose ciertas incongruencias, como las presentes en las voces entrada y entrar, la primera sin marca y con la indicación «En algunos deportes» y la

${ }^{9}$ Voz cuya ausencia es más injustificable todavía si se tiene presente el informe que la propia Corporación (19 de mayo de 2004) redactó en relación con su propuesta de que la expresión violencia doméstica sustituyera a expresiones como violencia de género o violencia familiar (http://www.rae.es/rae/gestores/gespub000001.nsf/(voAnexos)/arch BB81F7452A4355C0C12571F000438E7A/\$FILE/Violenciadegénero.htm).

${ }^{10}$ Los tecnicismos pueden aparecer de las formas siguientes: 1) marcados con tecn ('tecnicismo') cuando se usan frecuentemente en varios ámbitos; 2) con una definición unificada para todos ellos (retículo); 3) con la marca del ámbito al que se refiere exclusivamente (resonancia magnética o rinoplastia con Med., sulfato con Quím. o triodo con Fís.); 4) o sin marca, los que han pasado al dominio general (lumbago). 
segunda con la marca Dep. y sin la indicación anterior, cuando lo coherente hubiera sido que se abordaran técnicamente del mismo modo, al ser un sustantivo y un verbo referidos a la misma acción.

Los extranjerismos han frecuentado históricamente poco las páginas académicas. No obstante, desde la edición del DRAE-2001 se encuentran muchos más que en ediciones anteriores, pero se precisarían más detalles para que pudiera comprenderse en el DEst la toma de algunas decisiones al respecto: 1) hay extranjerismos que se escriben en cursiva-ballet [sic], ${ }^{11}$ best seller [sic] o hooligan [sic]-y otros no -airbag o forfait (forfait [sic] en DRAE-2001)-; 2) hay casos en los que la Academia decide adaptar la grafía extranjera a la española -belladona (de belladonna), bumerán (de boomerang), ñoqui [sic] (de gnocchi), pipermín (de pepper-mint), pulóver (de pullover) o güisqui [sic] (de whisky) - y no en otros -lobby [sic] (cuya adaptación podría ser *lobi), mezzosoprano [sic] (*medsosoprano), paddle [sic] (*pádel), panty [sic] (*panti), paparazzi [sic] (*paparadsi) o scooter [sic] (*escúter)-; 3) en el DEst no se incorporan extranjerismos que sí se recogen en el $D R A E-2001$ y que se usan hoy en día con frecuencia-baby-sitter [sic], bisnes [sic] (de business, bisnes en DRAE-2001), dancing [sic], footing [sic], mass media [sic]-; 4) hay voces que se incluyen tanto en el DEst como en el DRAE-2001 pero con algunas variaciones ortográficas -flashback [sic] (flash-back [sic] en el DRAE-2001), free lance [sic] (free-lance [sic] en el DRAE-2001)-; por último, la Academia suele adaptar al español las voces que en inglés terminan en -ing respetando su grafía original-casting [sic], catering [sic], holding [sic],jogging [sic], leasing [sic] o lifting [sic]-, aunque no siempre-mitin o travelín y no se recogen miting y traveling, pudiendo haber seguido el paradigma con casting [sic], catering [sic], footing [sic] o lifting [sic])-. No obstante la rica representación de extranjerismos, se echan en falta voces usadas desde hace años, como burka, chat -y sus derivados chateo y chatear-, doping, pay per view o tifosi, lo que contrasta con otras menos divulgadas que sí tienen cabida en el DEst, del tipo gin-fizz [sic] (como en el DRAE-2001).

Otros aspectos cuantitativamente menores siguen la línea de las soluciones tomadas por la Real Academia Española hasta ahora expuestas, como el tratamiento de las siglas -se anota que se registran las más usuales, y de hecho se incluye un buen número, pero no se encuentran muchas que los españoles usamos con frecuencia: $A T S, B O E, C O E, C O P E, C S I C, E T A$ (aunque sí está su derivado etarra), INEM, IRPF, ITV, ONCE, ONU, RAE, RENFE, SEAT o SERo el de algunos grupos léxicos, que deberían presentarse de manera más unificada -se lematiza driblar, pero no driblaje y dribling, en cambio sí sus sinónimos respectivos regatear y regate-. Sin embargo, se desmarca de esta asistematización la inclusión de los formantes (prefijos y sufijos) más importantes, lo cual ayuda al estudiante a la hora de establecer las relaciones léxicas en la formación de palabras.

\section{MiCROESTRUCTURA}

De los muchos aspectos de que trata la microestructura, a continuación se comentan los que inciden especialmente en el perfil del usuario al que se dirige la obra.

Se transcribe, entre comillas dobles, la pronunciación de los extranjerismos -holding (pal. ingl.; pronunc. «jóldin») o jacuzzi (pronunc. «yacúsi»)-y de los casos que presentan alguna dificultad a este respecto -texano, na. (pronunc. «tejáno»)-.

\footnotetext{
${ }^{11}$ Incluyo el latinismo sic entre corchetes al lado de las voces que se lematizan en cursiva en el DEst.
} 
Se omite la información etimológica. A priori, considerando el tipo de diccionario de que se trata, no parece que sea necesario dar a conocer el étimo de una palabra para usarla correctamente, pero, si tenemos en cuenta que la obra se dirige a estudiantes de secundaria, es posible que dicha información sea de utilidad, sobre todo, en voces homónimas, ${ }^{12}$ como en don ('regalo') y don ('tratamiento de cortesía'), en donde el conocimiento de la procedencia de las voces, la primera del latín DONUM y la segunda del latín DOMINUs, puede ayudar a que el estudiante aclare sus distintos sentidos. Este desconocimiento de la procedencia de algunas palabras lo encontramos en los medios de comunicación, en donde suelen aparecer usos nuevos de voces y expresiones latinas, como en el caso de versus (voz ausente en el DEst y en el DRAE2001), palabra usada frecuentemente con el significado de 'contra' cuando el etimológico es el de 'hacia' ( $c f$. verso en italiano o vers en catalán y francés).

La información gramatical presente en el DEst, que en general es suficiente al corresponderse con la preocupación creciente por parte de la lexicografía didáctica, podría ampliarse en algunos apartados. Se indica, por un lado, la categorización gramatical de las clases de palabras en forma de abreviatura, así como la subcategorización verbal, dividida en copulativo, intransitivo, pronominal y transitivo. No obstante, se espera que una obra de estas características aporte más información gramatical, pues un diccionario didáctico es también un diccionario de dudas. Por otro lado, se indica con regularidad el género de los sustantivos y la forma femenina de los adjetivos (curdo, da), y en especial de los nomina agentis, es decir, los nombres que designan una profesión o actividad -en arquitecto, ta; médico, ca; y presidente, ta, por ejemplo, se indica «m. y f. (A veces como f. se usa arquitecto / médico / presidente)», de lo cual se sobreentiende que las formas arquitecta / médica / presidenta están normalizadas en español-, así como los femeninos irregulares -emperador-emperatriz-y los plurales irregulares de los sustantivos y adjetivos (cambios prosódicos) - carácter (pl. caracteres) o espécimen (pl. especímenes)-. Sin embargo, se encuentran algunas irregularidades, como la indicación de la terminación anómala de las voces terminadas en -i tónica -alhelíes o alhelís para alhelí; esquíes o esquís para esquí-, que no siempre se señala -de baladí se indica en el ejemplo; de pedigrí no se muestra en ningún apartado-, o como la señalización del plural en los vocablos latinos que terminan en - $m$ en unos casos (memorándums) y en otros no (referéndum). Igualmente, se hallan varios aspectos mejorables: la ausencia de la indicación de la invariabilidad de algunas voces en la formación del plural (crisis); las relaciones no explicitadas entre sustantivos masculinos y femeninos formados con otras palabras (caballo-yegua); la no señalización de la pérdida de la tilde en la formación del femenino (grandullón, ona), siguiendo la tendencia de la lexicografía general del español (grandullón, $n a$ ); o la indicación del régimen preposicional de los verbos resaltada mediante la diferenciación tipográfica en los ejemplos - pensar 'intr. 5 Formar en la mente un juicio u opinión sobre algo. No pienses más EN ello'-, sin la dedicación de un espacio independiente en el artículo lexicográfico para referirse de manera explícita a ello.

En cuanto a la información sintáctica, la inclusión del contorno en la definición lexicográfica representa una novedad entre las obras académicas, en la línea de los diccionarios didácticos publicados en la última década que han venido manifestando una sensibilidad importante hacia los problemas de construcción (Bargalló 1999: 24). Se representa formalmente de dos modos: los complementos del lema se indican entre paréntesis - «debilitar. tr. Volver débil

${ }^{12}$ Como afirman Hernández (1991: 136) y Garriga (2002: 47), entre otros. 
o más débil (algo o a alguien)»- y el sujeto se presenta en un cuerpo de letra menor que el resto de palabras - «equivaler. (conjug. VALER). intr. Ser una cosa igual a otra en valor, efecto o significado»-. Con todo, aún debe estudiarse con más profundidad hasta qué punto la formalización de los aspectos contextuales del lema definido y de la propia definición es una información que el usuario, generalmente lego en materia lingüística, sabrá descodificar y aprovechar. Por ahora, responde más a una formalización metalexicográfica que a una necesidad real de los usuarios.

La redacción de las definiciones constituye la mejor aportación del DEst, pues se aproxima al estilo de las definiciones claras, concisas y exactas presentes en los diccionarios didácticos, elaboradas mediante el uso de un vocabulario restringido. $\mathrm{Si}$, a este respecto, se compara la definición de gato en el DEst con la del $D R A E-2001$, se observa que la del $D E s t$ se acerca al tipo de definición que aparece en la lexicografía didáctica (DISALE y DIPELE) y se aleja del enciclopedismo presente en el $D R A E$ :

\begin{tabular}{|l|l|}
\hline DEst & $\begin{array}{l}\text { Mamífero doméstico de pequeño tamaño, cabeza redonda, ojos brillantes y } \\
\text { pelaje suave y espeso, que suele cazar ratones. }\end{array}$ \\
\hline DRAE-2001 & $\begin{array}{l}\text { Mamífero carnívoro de la familia de los Félidos, digitígrado, doméstico, de } \\
\text { unos cinco decímetros de largo desde la cabeza hasta el arranque de la cola, } \\
\text { que por sí sola mide dos decímetros aproximadamente. Tiene cabeza redonda, } \\
\text { lengua muy áspera, patas cortas y pelaje espeso, suave, de color blanco, gris, } \\
\text { pardo, rojizo o negro. Es muy útil en las casas como cazador de ratones. }\end{array}$ \\
\hline DISALE & $\begin{array}{l}\text { Pequeño mamífero carnívoro, generalmente doméstico, de cabeza redonda, } \\
\text { ojos que pueden ver en la oscuridad, pelo suave y espeso, cola larga y patas } \\
\text { cortas con uñas retráctiles. }\end{array}$ \\
\hline DIPELE & $\begin{array}{l}\text { Animal mamífero doméstico de patas cortas y pelo espeso y suave, que es muy } \\
\text { hábil cazando ratones y sirve al hombre de compañía. }\end{array}$ \\
\hline
\end{tabular}

A pesar de lo adecuadas que resultan en general las definiciones en el DEst, convendría saber si la Academia ha empleado un número limitado de definidores, como resuelve el $D I$ $P E L E$, o no, ya que la unificación de criterios a la hora de escoger los hiperónimos es fundamental en cuanto se refiere a la selección del léxico y a la fijación de la coherencia interna en la obra.

Por lo que respecta a las informaciones pragmáticas -si el uso de una palabra es coloquial, elevado, formal, familiar, humorístico, jergal, técnico, vulgar, etc.-, que en los diccionarios se suelen mostrar mediante las marcas de uso, el DEst coincide con la lexicografía didáctica al proporcionar abundante información, aunque con algunas salvedades. A este respecto, por ejemplo, los sinónimos marcados de homosexual o gay se marcan como sigue: bujarrón (jerg. despect.), invertido (eufem. despect.), julandrón (jerg. despect.), marica (coloq. despect. Se usa como insulto), maricón (malson. Se usa como insulto), ${ }^{13}$ mariposa (coloq., despect.), mariposón (coloq., despect.), mariquita (coloq., despect. Se usa como insulto) o sarasa (coloq., despect.). Ciertamente, marica, maricón y mariquita se emplean como insulto, pero buja-

${ }^{13}$ Marcado con vulgar en el DRAE-2001. Los límites que se establecen con las marcas connotativas «despectivo», «peyorativo» y «vulgar» no quedan claros en el DRAE-2001. El DEst descarta el empleo de «peyorativo»-indicación frecuente, por ejemplo, en un diccionario como el DISALE-, que en el DRAE-2001 sólo se emplea en 9 casos. 
rrón, invertido, julandrón, mariposa y sarasa también podrían usarse para insultar. Ello demuestra que la metalexicografía tiene mucho camino por recorrer en el terreno de la pragmática, a pesar de los esfuerzos realizados en la última década, pues los principales problemas con los que se encuentran los diccionarios didácticos actuales tienen que ver con la subjetividad de dichas marcas de uso. ${ }^{14}$ En estos casos, la intención comunicativa es la que determina, junto con el apoyo de estudios basados en corpus textuales, si se puede usar o no como insulto.

Por otra parte, el sistema de marcación temática presenta variaciones notables en comparación con la edición del $D R A E$-2001. De las 72 marcas de especialidad que se emplean en la última edición del diccionario mayor, en el DEst se usan 52. Por una parte, se incluyen 2 de las 5 marcas nuevas añadidas al DRAE-20015 -Constr. (Construcción) y Heráld. (Heráldica)y, por otra, se excluyen 32 marcas con respecto al $D R A E-2001 .{ }^{16}$ Además, se reincorporan 7 que se eliminaron en el $D R A E-2001{ }^{17}$ y se crean 5 nuevas para el DEst: Coc. (Cocina), Enseñ. (Enseñanza), Gráf. (Artes Gráficas), Of. (Oficios), Period. (Periodismo) y Prehist. (Prehistoria). La exclusión de las marcas Alq., Cron., Danza, Hist. y Teatro puede justificarse por su poca presencia en el DRAE-2001, pero no así la de Astron. (bajo 304 acepciones) o la de Geom. (bajo 409).

Las acepciones se dividen en dos bloques: acepciones simples y formas complejas. En cuanto a su ordenación, lo deseable sería que un diccionario dirigido a estudiantes de secundaria ordenara sus acepciones por frecuencia de uso (Hernández 1991: 138-139). En el DEst se hallan casos en los que las acepciones se organizan a partir del criterio de uso y otros por el criterio etimológico, mediante la intercalación del signo ${ }^{\circ}$ para establecer las subdivisiones dentro de una misma categoría -s.v. operar (tr., tr. prnl. e intr.)- y del signo • para indicar el cambio de categoría gramatical dentro del artículo lexicográfico -s.v. más (adv., adj., pron y $\mathrm{m}$.)-. Por ejemplo, véanse los distintos criterios usados en los siguientes casos:

\begin{tabular}{|c|c|}
\hline ariete & azafata \\
\hline $\begin{array}{l}\text { 1. histór. Máquina militar para derribar } \\
\text { murallas, consistente en una viga larga y } \\
\text { pesada, reforzada en un extremo con una } \\
\text { pieza metálica, frec. en forma de cabeza } \\
\text { de carnero. [...] 2. Dep. En el fútbol: } \\
\text { Delantero centro. [...] }\end{array}$ & $\begin{array}{l}\text { 1. Mujer encargada de atender a los } \\
\text { pasajeros a bordo de un avión. [...] } 2 . \\
\text { mujer que proporciona información y } \\
\text { ayuda al público en exposiciones, } \\
\text { congresos u otros eventos. [...]. 3. Criada } \\
\text { de la reina que se ocupaba de sus vestidos } \\
\text { y alhajas. [...] }\end{array}$ \\
\hline
\end{tabular}

${ }^{14}$ Véanse, a este respecto, los trabajos de Garriga (1999) y Moreno (2000), en donde se alude a que el hecho de dar a las marcas una forma adecuada y objetiva es un escollo que debe salvar la lingüística hispánica en su conjunto.

${ }^{15}$ Constr. (Construcción), Ecd. (Ecdótica), Heráld. (Heráldica), Telec. (Telecomunicación), Transp. (Transportes).

${ }^{16}$ Acúst. (Acústica), Alq. (Alquimia), Astron. (Astronomía), Carp. (Carpintería), Cineg. (Cinegética), Cinem. (Cinematografía), Cron. (Cronología), Danza (Danza), Ecd. (Ecdótica), Electr. (Electricidad), Equit. (Equitación), Esc. (Escultura), Esgr. (Esgrima), Estad. (Estadística), Fotog. (Fotografía), Genét. (Genética), Hist. (Historia), Impr. (Imprenta), Métr. (Métrica), Mit. (Mitología), Náu. (Náutica), Numism. (Numismática), Ópt. (Óptica), Ortogr. (Ortografía), Pint. (Pintura), Rét. (Retórica), Teatro (Teatro), Tecnol. (Tecnología), Telec. (Telecomunicación), Topog. (Topografía), Transp. (Transportes) y Veter. (Veterinaria).

${ }^{17}$ Astrol. (Astrología), Electrón. (Electrónica), Encuad. (Encuadernación), Fisiol. (Fisiología), Lit. (Literatura), Mineral. (Mineralogía) y Polit. (Política). 
Como se observa, en ariete los sentidos se ordenan mediante el criterio etimológico (el primero marcado con histór. y el segundo con Dep.). Sin embargo, los sentidos de azafata aparecen ordenados por criterios de uso.

Las formas complejas se tratan ampliamente -véanse, por ejemplo, las recogidas bajo decir, hueso u ojo-, pero un análisis sucinto de la representación de estas formas demuestra que queda mucho camino por avanzar. Es cierto que existen obras especializadas que tratan exclusivamente estas formas -por ejemplo, el Diccionario fraseológico del español moderno de Fernando Varela y Hugo Kubarth (1994) o el Diccionario fraseológico documentado del español actual: locuciones y modismos españoles dirigido (2004) de Manuel Seco, Olimpia Andrés y Gabino Ramos-, pero un diccionario dirigido a estudiantes de secundaria tiene que ser capaz de ofrecerles soluciones al respecto. Desde el punto de vista formal, se advierte la necesidad de establecer un rigor mayor en la clasificación de las formas complejas, pues no se distingue entre sintagmas nominales, locuciones, colocaciones, modismos, etc., siguiéndose así el procedimiento de la lexicografía general publicada hasta el momento. Si bien en la presentación (DEst: XIX) se alude a que las formas complejas se dividen en lexías ${ }^{18}$-marcadas como nombres, como número romano- y en otras formas complejas -locuciones (verbales, adjetivas, etc., como el ojo derecho), expresiones (como por todos los santos) e interjecciones (como arrea)-, en el artículo del diccionario no se alude a un tipo de marcación lexicográfica explícita ni se indica cómo se recogen las formas complejas en su interior. Tradicionalmente, la Academia ha ordenado las expresiones formadas por varios vocablos, como las frases hechas, las locuciones, etc., en el artículo correspondiente a uno de los vocablos de que constan, a partir de un orden de preferencia: sustantivo o cualquier palabra usada como tal, verbo, adjetivo, pronombre y adverbio. Pero esto lo saben los lexicógrafos. El usuario no experto no lo conoce y, sobre todo, no lo conocerá si no se le explica. Por otra parte, se establecen algunas diferencias mediante el uso de una simbología específica, pero son difícilmente distinguibles si pensamos en el usuario que manejará la obra. Así, el símbolo $\square$ señala el comienzo del apartado destinado a las formas complejas -cada dos por tres, s.v. dos-, el símbolo $\square$ separa las lexías dentro de las formas complejas -abrir los ojos, s.v. ojo-, el símbolo - separa entre sí las distintas formas complejas - una pasta gansa, s.v. pasta-, y el símbolo $\square$ separa las acepciones de una forma compleja cuando tienen distinta categoría o subcategoría gramatical - a pedazos o en pedazos, s.v. pedazo-. Si observamos la representación de las colocaciones, se notan algunas inconsistencias fruto de la falta de tratamiento específico por parte de los lexicógrafos, a su vez, efecto de la inexistencia de un reconocimiento teórico delimitado: así declararse un incendio no está ni bajo declarar ni bajo incendio -del mismo modo locamente enamorado-, pero, en cambio, armar un escándalo sí viene especificada:

escándalo m. 1. Alboroto o ruido grandes. Frec. con v. como armar o armarse. Podéis jugar, pero sin armar escándalo. Por cualquier cosa monta un escándalo.

Por otra parte, se encuentran colocaciones como poder adquisitivo, correr el rumor, zanjar una cuestión que sólo se representan en los ejemplos, sin que se indique que se trata de palabras que aparecen frecuentemente combinadas, en la misma línea de los diccionarios didácticos hasta hoy publicados (Bargalló 1999: 28).

${ }^{18}$ Voz no recogida en el DEst. 
Las relaciones paradigmáticas -sinónimos y antónimos- ocupan, como en los diccionarios didácticos, ${ }^{19}$ un lugar considerable. En el DEst, se emplea el signo > para presentar los sinónimos y afines - «palabras que, sin ser sinónimos perfectos (los cuales raramente existen), tienen un significado próximo al de la voz estudiada» (DEst: XXII)-. En este apartado, la regularidad en la presentación de la información es mejorable. Si regresamos a los sinónimos de homosexual, se observa que mariposa, mariposón y sarasa vienen marcados como «coloq., despect. » y definidos como 'Hombre afeminado u homosexual' pero, en cambio, las interrelaciones sinonímicas no se explicitan. La remisión se encuentra bajo homosexual, que envía a gay y a lesbiana, y bajo gay, que remite a homosexual, precedido de un asterisco (*) para señalar que se trata de un sinónimo básico. Además, es en este apartado, en el de las remisiones, en donde la concepción castellana del español de España como el modelo de lengua estándar se percibe con mayor claridad, a pesar de que se afirma que el léxico recogido es el «del español general de España y América, prescindiendo de los usos regionales y locales» (DEst: XVI). Por ejemplo, si se contrastan las definiciones de autobús y de guagua, la primera se define como '1. Vehículo automóvil de gran capacidad, destinado al transporte de pasajeros, frec. con trayecto fijo y urbano', mientras que la segunda se define como «frecAm. Autobús», enviando de forma indirecta y unidireccional a autobús, sin la «necesidad» de definir su significado. La definición de autobús es neutra, no va acompañada de información diatópica, a pesar de no tratarse de una voz panhispánica, y tampoco remite a guagua, mientras que ésta, voz tan neutra como autobús en los lugares en los que se emplea, se presenta marcada diatópicamente con la abreviatura que indica 'frecuente en América'. Es decir, que guagua significa 'autobús', lo cual va dirigido de modo exclusivo a un solo tipo de usuario, el que sabe lo que es el autobús. Este criterio no se adopta siempre del mismo modo, pues en el caso de chequear - 'Hacer un chequeo (a alguien o algo)'- y checar -'Am. Chequear (algo)'-, por ejemplo, la remisión es bidireccional. Dicho esto, la ausencia de sinónimos de homosexual empleados en América es coherentemente presagiable, como balín en Argentina, chivo en Perú, galleta en Colombia, marolo en México o parcha en Venezuela.

Un aspecto de la microestructura que la Real Academia recupera de su primer diccionario, el Diccionario de Autoridades (1726-1739), es el de los ejemplos. En el DEst, las acepciones suelen ir acompañadas de ejemplos de uso, extraídos de un banco de datos léxicos específicos creado ad hoc «integrado exclusivamente por libros de texto de todas las materias» (DEst: Xv) y apoyado en otros archivos ya existentes en la institución, como el $C R E A$. Estos ejemplos de uso se ofrecen en forma de frases-ejemplo, pues permiten ilustrar muchos aspectos sin la necesidad de que se tenga que ahondar en ellos de manera explícita. En cuanto a los ejemplos en los que se han basado los autores, si bien reales, no queda claro que sean literales o modificados. En la presentación, se indica que el diccionario se ha realizado «con el apoyo constante de ejemplos de uso real» (DEst: IX) y, cuando se refiere explícitamente a las voces de América, se señala que «son citas exactas o casi exactas de textos americanos, tomadas del $C R E A »$ (DEst: XXII). Asimismo, sería práctico que se explicaran los criterios que se han llevado a cabo para la selección de los ejemplos. Por otra parte, se menciona que en los ejemplos

${ }^{19}$ En Nomdedeu (2006) se indica que la simbología empleada para señalar los sinónimos en la lexicografía didáctica es demasiado variada. Para los sinónimos y antónimos, respectivamente, se emplean los signos $\rightarrow / \leftrightarrow(D I-$ $P E L E)$, ANT. (DEPE), SIN. (DISALE) y $\bullet$ SIN./ANT. (DILEPEE). 
pueden aparecer «voces no incluidas en el cuerpo de la obra. Puede ocurrir esto con más frecuencia en ejemplos americanos, extraídos directamente del CREA» (DEst: XXII). Por lo tanto, no parece que se haya realizado una labor de selección íntegra, ya que el hecho de que un buen ejemplo de uso contenga palabras no usadas, es decir, no recogidas por este diccionario, puede resultar contradictorio. Finalmente, destaca el hecho de que las voces y acepciones malsonantes (marcadas con malson) son las únicas que no vienen ejemplificadas. La Academia no explica las razones de esta ausencia, pero, no obstante, se entrevé un criterio supuestamente purista y con afán educador que está al margen de consideraciones estrictamente lingüísticas. ${ }^{20}$ Una voz como mierda, obviamente no ejemplificada en el $D E s t$, se ejemplifica con normalidad, por ejemplo, en el DISALE:

mierda 3 VULGAR; INSULTO. Cosa despreciable, mal hecha o de poco valor: El concierto fue una mierda. Sin. bodrio, caca.

La Real Academia Española considera que una voz malsonante es aquella «que ofende al pudor, al buen gusto o a la religiosidad» y, claro está, el lenguaje socialmente sancionado se opone a los conceptos de pureza y de calidad que intervienen en la definición de la lengua estándar.

En definitiva, hay algunos aspectos que la Academia pudiera haber mejorado a partir de la consideración de los importantes avances que se están produciendo en la lexicografía didáctica, como, por ejemplo, una inclusión más objetiva de los diferentes españoles hablados en América, una muestra más fiel de las voces actuales, una mayor coherencia en la representación de extranjerismos y de formas complejas, la incorporación de informaciones etimológicas o el establecimiento de una mejor relación entre sinónimos y antónimos. Del mismo modo, sigue echándose en falta la aportación de más detalles que permitan explicar la toma de algunas decisiones, como la lematización de las voces o la selección de los ejemplos. No obstante, la Academia ha publicado una obra sin precedentes en la propia Corporación desde la aparición del Diccionario de Autoridades, pues el DEst ofrece abundante información pragmática, tanto en el sistema de marcación como en los ejemplos, y la redacción de unas definiciones pensadas para el usuario de la obra. Por lo tanto, aunque todo diccionario es perfeccionable, la publicación del $D E s t$ contribuye a mejorar de manera significativa la oferta de diccionarios didácticos de español.

\section{REFERENCIAS BIBLIOGRÁFICAS}

BARGALLÓ EsCRIVÀ, Maria (1999): «La información gramatical en los diccionarios didácticos monolingües del español», en $\mathrm{M}^{\mathrm{a}}$ Neus Vila et al., eds., Así son los diccionarios, Lleida, Universidad de Lleida, pp. 15-42.

${ }^{20}$ Criterio inexistente en el Diccionario de Autoridades: «mierda. s.f. En su riguroso sentido significa toda suciedad; pero se entiende por lo comun por el excremento del hombre. Lat. Merda. Pinc. Philos. Epist. 9. Fragm. 4. La qual seria más ridícula si fuese mas fea: como de uno, que recibiendo olór malo, dixo: O es mierda o assan torreznos». 
Castillo Carballo, Auxiliadora y José Manuel García Platero (2003): «La lexicografía didáctica», en Antonia Ma Medina Guerra, coord., Lexicografia española, Barcelona, Ariel, pp. 333-351.

GARriga Escribano, Cecilio (1999): «Diccionarios didácticos y marcas lexicográficas», en $\mathrm{M}^{\mathrm{a}}$ Neus Vila et al., eds., Así son los diccionarios, Lleida, Universidad de Lleida, pp. 43-75.

(2002): «Los diccionarios escolares», en Textos de Didáctica de la Lengua y de la Literatura, 31 , pp. 35-52.

GutiÉRrez CuAdrado, Juan (1996): «Las marcas en los diccionarios para extranjeros», en Pilar Díez de Revenga y José Ma Jiménez Cano, eds., Estudios de sociolingüística, Murcia, DM, pp. 95-106.

HERnÁNDEZ HERNÁNDEZ, Humberto (1991): «Sobre el concepto de «acepción»: revisiones y propuestas», Voz y Letra, II, pp. 127-141.

(1992): «Los diccionarios de uso del último decenio (1980-1990): estudio crítico», en EURALEX'90 Proceedings. Actas del V Congreso Internacional, Benalmádena (Málaga), 28 agosto-1 septiembre 1990, Barcelona, Bibliograf, pp. 473-481.

(2000): «Últimas tendencias en la lexicografía didáctica», en Stefan Ruhstaller y Josefina Prado Aragonés, eds., Tendencias en la investigación lexicográfica del español. El diccionario como objeto de estudio y didáctico, Actas del Congreso celebrado en la Universidad de Huelva, del 25 al 27 de noviembre de 1998, Huelva, Universidad de Huelva, pp. 101-115.

(2003): «La lexicografía escolar del español: desde sus orígenes hasta su consolidación», Revista Internacional de Lingüística Iberoamericana, I, pp. 7-25.

MALDONADO, Concepción (2003): «La lexicografía didáctica monolingüe en español», en M Antonia Martín Zorraquino y José Luis Aliaga Jiménez, eds., La lexicografía hispánica ante el siglo XXI. Balance y perspectivas. Actas del Encuentro de lexicógrafos celebrado en Zaragoza, en el marco del Centenario María Moliner, los días 4 y 5 de noviembre de 2002, Zaragoza, Gobierno de Aragón, pp. 129-150.

Moreno FernÁNDEZ, Francisco (2000): «Diccionarios para el aprendizaje de lenguas extranjeras», en Stefan Ruhstaller y Josefina Prado Aragonés, eds., Tendencias en la investigación lexicográfica del español: El diccionario como objeto de estudio lingüístico y didáctico. Actas del congreso celebrado en la Universidad de Huelva del 25 al 27 de noviembre de 1998, Huelva, Universidad de Huelva, pp. 151-170.

Nomdedeu Rull, Antoni (2006): «Diccionarios monolingües de aprendizaje de E/LE: características y uso», en Annali della Università degli Studi di Napoli “L'Orientale”. Sezione Romanza, XLIX, 2, pp. 397-431.

SÁNCHEZ MuÑoz, Trinidad (2002-2003): «Los diccionarios escolares a comienzos del siglo XXI»,Revista de Lexicografía, Ix, pp. 175-188. Antoni Nomdedeu Rull (Università degli Studi di Napoli «L'Orientale») 